\title{
Design of PWM Switching Power Amplifier for Active Magnet Bearing
}

\author{
Guoxiang Zhang \\ Tianjin Key Laboratory of Information Sensing and \\ Intelligent Control, \\ Tianjin University of Technology and Education \\ Tianjin, China \\ styh1225@163.com
}

\author{
Lei Huang \\ Tianjin Key Laboratory of Information Sensing and \\ Intelligent Control, \\ Tianjin University of Technology and Education \\ Tianjin, China \\ tutehl@163.com
}

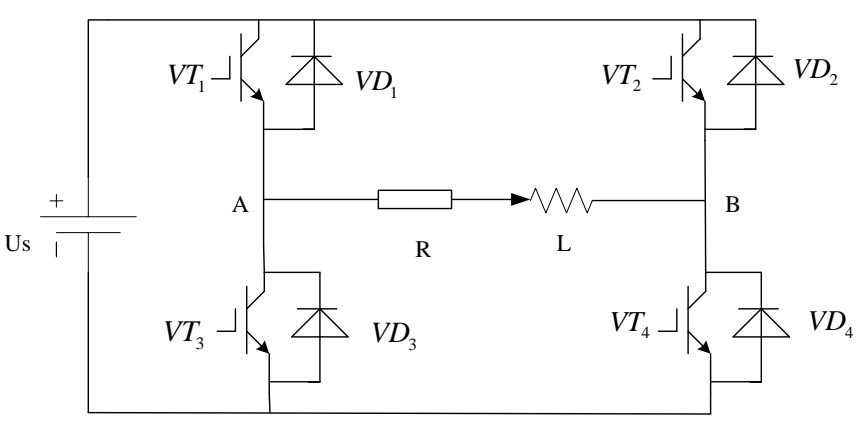

\begin{abstract}
Electrical control system plays a decisive role in the running performance for a permanent magnet biased magnetic bearing. Power amplifier, as a part of the electronic control system, its performance directly affects the suspension system. Therefore, the amplifier design is an important part of the system. A three-level switching power amplifier is presented in this paper, which uses a three-level PWM switching scheme. The implementation of the hardware and control strategy is explained in detail. Simulation and experiment results show that with the fullbridge three-level PWM switching power amplifier, it can provide bidirectional current and meet the needs of current control of magnetic bearings. Thus it may improve the DC bus voltage to increase the dynamic circuit performance while reducing current ripple.
\end{abstract}

Keywords-Magnet Bearing; Three-level Switching Power Amplifier; Current Ripple; PWM

\section{INTRODUCTION}

Power amplifier, as a part of the electronic control system, its performance directly affects the suspension system. Therefore, the amplifier designing is an important part of the system. Switching power amplifier is generally used in magnetic bearings, which is consisting by PI controller, PWM generator, main power circuit and current sensor. The role of an amplifier is to transfer the output signal into the control current by the switch power devices [1-5].

This paper applies a full bridge topology in the main circuit for the reason that the permanent magnet biased magnetic bearing with the general needs current to flow in both directions. Its current ripple is almost independent with the power supply voltage. Bidirectional three-level switching power amplifier can provide bidirectional current and meet the needs of current control of magnetic bearings. Thus, it may improve the DC bus voltage to increase the dynamic circuit performance while reducing current ripple [6]-[10]. According to the characteristics of permanent magnet biased magnetic bearing, this paper designed a three-level switching power amplifier.

\section{THREE-LEVEL SWITHCHIN® OWER AMPLIFIER}

Fig. 1 shows the topology of a full-bridge switching power amplifier, where $\mathrm{R}$ and $\mathrm{L}$ are respectively the resistance and inductance of the equivalent magnetic bearing coil.
Figure 1. Full bridge topology of the switching power amplifier

When a three-level PWM switching power amplifier is on work, the switch control signals of the power device VT1 and VT3 are complementary, and the switch control signals of VT2 and VT4 are also complementary; additionally, the phase difference of VT1, VT4 is T/2 (T is a switching cycle), and the phase difference of VT2, VT3 is also T/2.

Switching function S1 and S2 is introduced to describe the off-and-on-state of the switch, as is defined as follows:

(1)

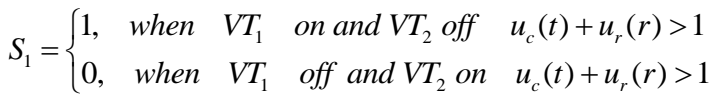

$$
S_{2}=\left\{\begin{array}{lllll}
1, & \text { when } & V T_{2} & \text { on and } V T_{4} \text { off } & u_{c}(t)+u_{r}(r)>1 \\
0, & \text { when } & V T_{2} & \text { off and } V T_{4} \text { on } & u_{c}(t)+u_{r}(r)>1
\end{array}\right.
$$

(2)

Where $\mathrm{Uc}(\mathrm{t})$ is the carrier signal of the triangular wave, $\mathrm{Ur}(\mathrm{t})$ is the output signal of PI controller.

For a two-level switching power amplifier circuit, considering that the power switch on-resistance and the forward diode resistance are both very small, and the equivalent resistance of the coil magnetic bearings is also very small [6], we can approximate the current ripple as

$$
\Delta i_{A B} \approx \frac{U_{s}}{2 f L}
$$

For a three-level switching power amplifier, its current ripple can be approximated as

$$
\Delta i_{A B} \approx \frac{U_{V D}+U_{O N}+U_{R}}{2 f L}
$$


Where Uvd is the voltage drop of the forward diode; UON is the voltage drop of the power switch conduction; UR is the voltage drop of the equivalent resistance of the coil magnetic bearing.

Compared (3) with (4), it can be seen that in a twolevel switching amplifier, while the switching frequency is same, the current ripple is proportional to the DC bus voltage; and the current ripple will increase accordingly when the DC bus voltage is increased to obtain an improved speed response of the current. Therefore, it can be conclusion that three-level PWM switching amplifier technology can greatly reduce the output current ripple in the same average current value output.

Fig. 2 shows the control system structure of a threelevel switching power amplifier. Because PWM modulation is used in the system, the choice of switching frequency is very important for the system design. From (4), it is known that the higher the switching frequency is, the smaller the current ripple is. Furthermore, the higher the power switch switching frequency is, the lower the power device switching efficiency is. Therefore, the switching frequency should be taken in an appropriate range to solve the contradictions between the dynamic characteristics, the frequency and power devices.

According to the sampling theorem, there is

$$
f_{k} \geq 10 f_{e}
$$

Where $\mathrm{fk}$ is the switching frequency of the amplifier, fe is the upper limit of the cut off frequency for the amplifier.

When the designed speed of the magnetic bearing is $60,000 \mathrm{rpm}$, the fundamental frequency of control current is $1 \mathrm{k} \mathrm{Hz}$. Therefore, switching power amplifier frequency can be selected $10 \mathrm{k} \mathrm{Hz}$ to meet the above requirements.

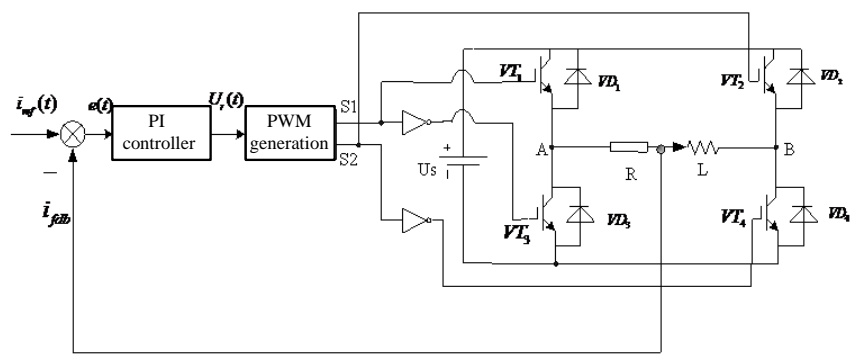

Figure 2. Control diagram of three-level switching power amplifier

\section{SiMULATION RESEARCH}

According to the system control block diagram, the three-level PWM switching power amplifier control system is built on based on MATLAB/SIMULINK simulation platform. And a simulation comparison is made with the two-level PWM switching power amplifier. System parameters for Simulation and experimental are shown in Table 1.
TABLE I. PARAMETERS OF THREE-LEVEL SWITCHING POWER AMPLIFIER

\begin{tabular}{ll}
\hline Parameter entry & Parameter values \\
\hline AMB equivalent resistance $/ \Omega$ & 1.6 \\
AMB equivalent inductance $\mathrm{L} / \mathrm{mH}$ & 8.5 \\
Triangular wave carrier frequency f/Hz & $10 \mathrm{~K}$ \\
DC bus voltage /V & 100 \\
MOSFET Resistance (IR640) / $/ \mathrm{H}$ & 0.15 \\
Freewheeling diodes the forward voltage & 1.3 \\
drop (HFA25TB60)/V &
\end{tabular}

Fig. 3 (a) and Fig. 4 (a) are the reference and following simulating waveform at the sine signals of amplitude $1 \mathrm{~A}$, frequency $20 \mathrm{~Hz}$ respectively for two level and three-level PWM switching power amplifiers respectively. Fig. 3 (b) and Fig. 4 (b) the current ripple of sine signal input of amplitude $1 \mathrm{~A}$, frequency $20 \mathrm{~Hz}$ of two level and three-level PWM switching power amplifiers respectively.

It can be seen that maximum of current ripple is $0.015 \mathrm{~A}$ in the way of three-level, while it is $0.06 \mathrm{~A}$ in the way of two-level mode. Compared with the simulation results of two methods, it shows that three-level PWM method greatly reduces the magnetic bearing switching power amplifier current ripple than the traditional twolevel method.

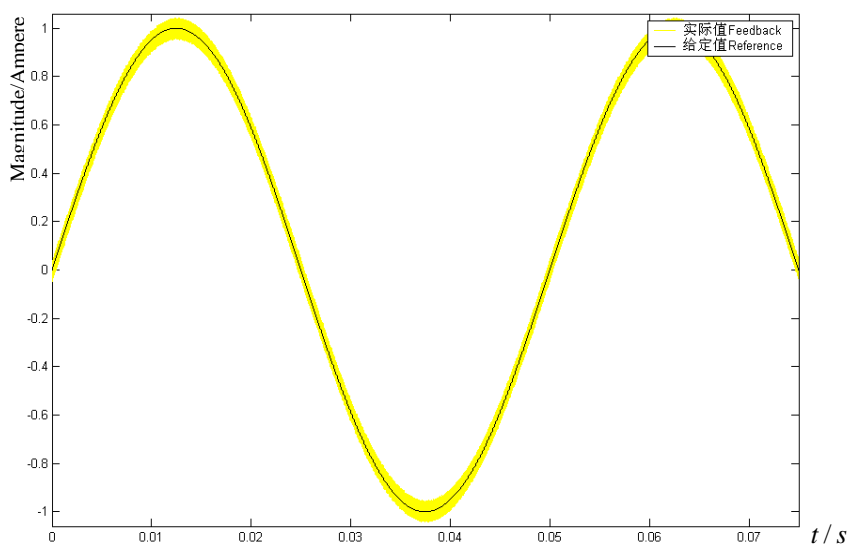

(a) 


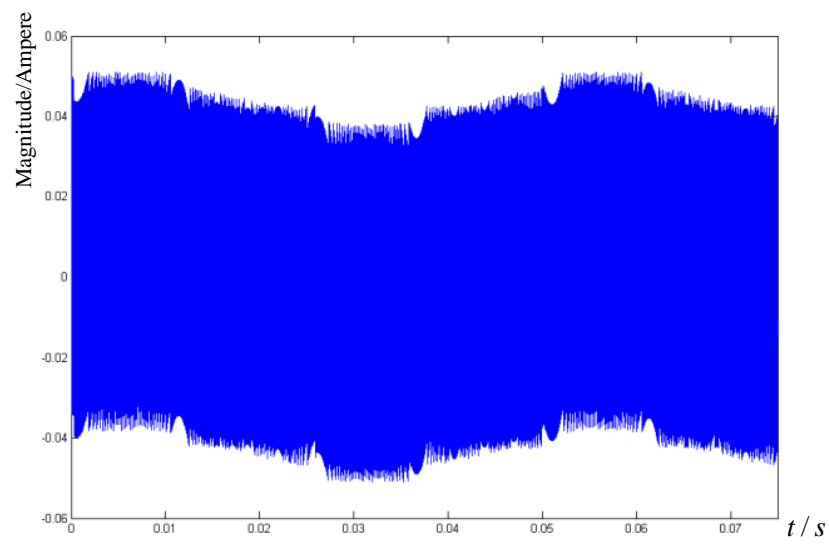

(b)

Figure 3. The reference, feedback and error simulating waveforms of $20 \mathrm{~Hz}, 1 \mathrm{~A}$ two-level current signal

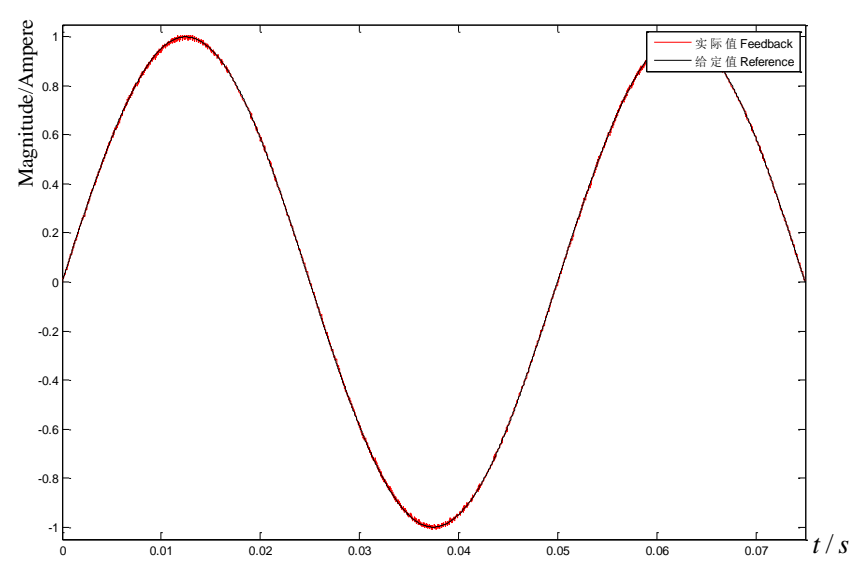

(a)

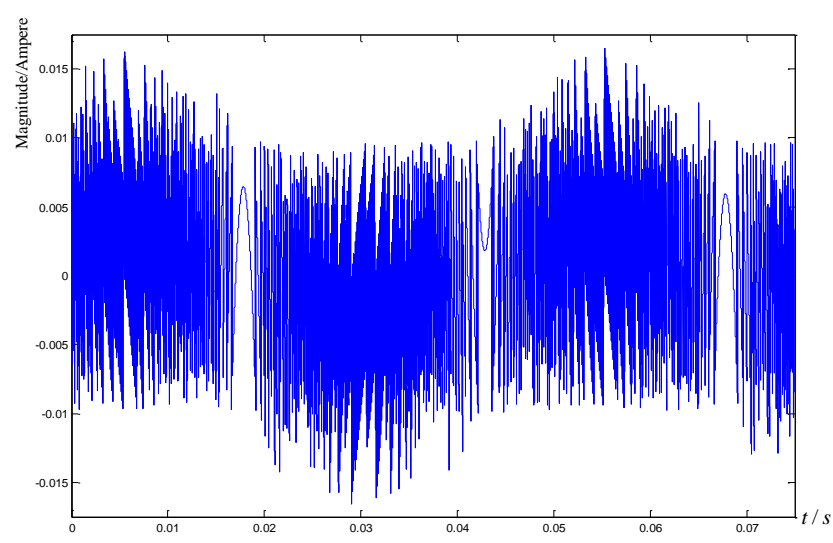

(b)

Figure 4. The reference, feedback and error simulating waveforms of $20 \mathrm{~Hz}, 1 \mathrm{~A}$ three-level current signal

\section{EXPERIMENT RESEARCH}

Experimental three-level PWM switching power amplifier have the same hardware as the traditional two level PWM switching power amplifier, except for the control program in the DSP PWM signal generation in different ways. Fig. 5 is the reference and following current waveforms for $50 \mathrm{~Hz}, 1.4 \mathrm{~A}$ two-level mode. Fig. 6 is the reference and following current waveforms for $50 \mathrm{~Hz}, 1.4 \mathrm{~A}$ three-level mode. Comparison of experimental results shows the same three-level PWM switching power amplifier has the advantages of the current ripple.

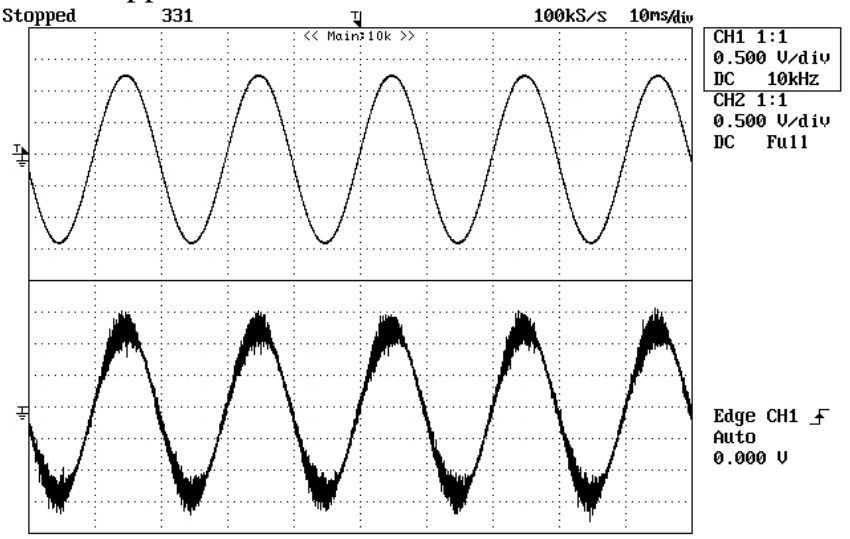

Figure 5. The reference and following current waveforms for $50 \mathrm{~Hz}$ 1.4A two-level mode

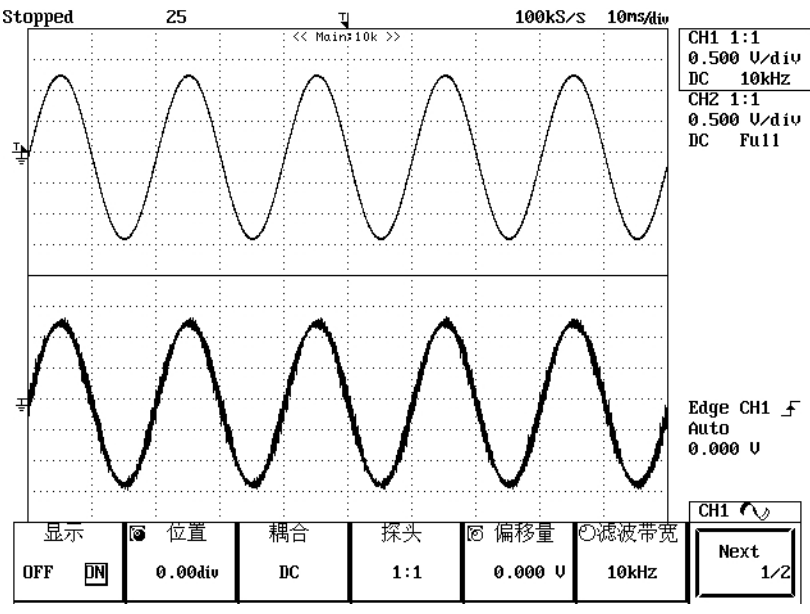

Figure 6. The reference and following current waveforms for $50 \mathrm{~Hz}$, $1.4 \mathrm{~A}$ three-level mode

\section{CONCLUSION}

Theoretical analysis, simulation and experiment results show that the proposed full-bridge three-level PWM switching power amplifier is able to provide bidirectional current magnetic bearings, magnetic bearings designed to meet the needs of current control may improve the DC bus voltage to increase the dynamic circuit performance while reducing current ripple.

\section{REFERENCES}

[1] Zhang Liang, Fang Jiancheng. Analysis of current ripple and implementation of pulse width modulation switching power 
amplifiers for active magnetic bearing[J]. Transactions of China Electrotechnical Society. 2007, 22(3): 13-20.

[2] LI Yang, DAI Peng, YU Yuesen. Overview of the SVPWM overmodulation strategies of three-level inverter $[\mathrm{J}]$. Electric Drive,2010,40(7):8-11

[3] Zeng Xueming, Xu Longxiang, Liu Zhengxun. Study of three level PWM power amplifier for AMB[J]. Power Electronics,2002,36 (3) $: 13-15$.

[4] Zang Xiaomin, Wang Xiaolin, Qiu Zhijian,et al. Research on current mode tri-state modulation technology in switching power amplifier for magnetic bearings[J]. Proceedings of the CSEE,2004,24(9):167-172.

[5] Zang Xiaomin,Wang Xiaolin,Qiu Zhijian,et al.An improved current-controlled tristate switching power amplifier for magnetic bearings based on sample-hold strategy[J].Transactions of China Electrotechnical Society, 2004,19(10):85-90.
[6] Wang Jun Xu Longxiang. Equivalent Mathematical Models of Switching Power Amplifier for Magnetic Bearing [J]. Transactions of China Electrotechnical Society.2010,25(4):53-58.

[7] Xu Yanliang, Dun Yueqin,Wang Xiuhe. Analysis of hybrid magnetic bearing with a permanent magnet in the rotor by FEM [J]. IEEE Trans. Magn, 2006, 42(4):1363-1366.

[8] Wang Jun,Xu Longxiang.Parallel resonant DC link soft-switching power amplifier of magnetic bearing[J]. Proceedings of the CSEE, 2009,29(12):87-92

[9] Han Fujun, Fang Jiancheng, Liu Gang. Design and implementation of SVPWM switching power amplifiers for active magnetic bearing [J].Transactions of China Electrotechnical Society. 2009,24(5):119-124.

[10] Li Bing, Deng Zhiquan, Yan Yangguang.Current mode switching for tri-state amplifiers in magnetic bearing control system supporting high speed motors[J].Power Electronics, 2003,37(4): 5255 . 